\title{
Experimental study of transient pressures generated by the impact of a liquid-liquid system
}

\author{
R. P. Dias ${ }^{1}$, J. G. Dalfré Filho ${ }^{2}$ \& A. I. B. Genovez ${ }^{2}$ \\ ${ }^{I}$ College of Civil Engineering, Architecture and Urbanism, \\ Unicamp, Brazil \\ ${ }^{2}$ Water Resources Department, Unicamp, Brazil
}

\begin{abstract}
The failure of a structure, either hydraulic or coastal, may be caused by pressure propagation and distribution generated by a fluid impact, that produces uplift pressure. The mechanics of wave impacts are still not properly understood and is a complicated problem, mainly due to the fact that the water interacts with the surrounding air and the air is more compressible than water. The objective of this work was to understand the behaviour of a pressure pulse, generated by a liquidliquid impact, propagating by a two-phase flow. An experimental facility was constructed, consisting of an upper reservoir and a lower chamber attached to a horizontal steel pipe equipped with pressure transducers. The facility enabled the impact of two masses of water and the propagation of a pressure pulse along the horizontal pipe. The impact generated pressure transients of high intensity. The presence of air in the mixture influenced the duration of the transient and decreased peak pressures.
\end{abstract}

Keywords: transient pressures, impact liquid-liquid, aeration, experimental study.

\section{Introduction}

The failure of a structure, either hydraulic or coastal, may be caused by pressure propagation and distribution generated by the fluid-solid impact, that produces uplift pressure. Therefore, several researchers conducted studies in order to 
understand the energy propagation in these structures. Bollaert and Schleiss [1] according to Betancourt [2] studied pressures in a joint model impinged by a water jet. The authors pointed out that the pressure propagation is not linear and depends on the air content of the flow.

Hydraulic structures such as channel spillways, dissipation basins and concrete revetment of earth dams have to be protected against high uplift pressures in joints due to turbulent flows. Nevertheless, these structures may be subjected to the combined effect of the uplift pressure and the impact of a mass of water.

In the case of coastal structures, breaking waves produce a high shock pressure of short duration, followed by a quasi-hydrostatic regime, in which the pressure is much lower and slower than the previous one. If the sea wall contains a crack, pressure pulses can travel through the fluid and propagate into the crack. These pulses can cause high stresses and may cause the blocks to move. The pressure peaks are followed by a longer lasting but smaller hydrodynamic pressure, which is caused by the reflected wave crest (Muller et al. [3]). The impact pressures put severe loadings on structures, and may even travel into water filled cracks, pressing individual blocks outwards. Similar damage scenarios were reported from dykes with clay cover or revetment block protection.

The mechanics of wave impacts are still not properly understood and is a complicated problem, mainly due to the fact that the water interacts with the surrounding air and the air is more compressible than water. The air between a structure and an approaching wave may be expelled, entrapped or entrained. The violence of the wave impact frequently causes the air pocket to subdivide and the resultant bubbles can remain entrained in the water for a significant length of time (Bullock et al. [4]). The authors conducted laboratory drop tests using seawater and freshwater and demonstrated that maximum impact pressures and rise times are influenced by the level of aeration and the violence of the impact. According to the authors, entrained air has shown to reduce maximum impact pressures. A relation was derived enabling the reduction in impact pressure by aeration of flow.

Bagnold [5] was the first to demonstrate that the pressure in a fixed point on a vertical wall, during impact, initially rises to a peak value and then decreases (Cox and Cooker [6]). A series of model tests showed that the propagation of wave impact pressures into water filled cracks caused damages to coastal blocks structures. The experiments described the impact generated by pressure pulses traveling along water filled cracks, whereby the pressure magnitude decreased with increased travel distance, from $1.50 \%$ to $2.50 \%$ content of air, in the form of micro bubbles (Muller et al. [3]).

In Wolters and Muller [7] the authors analysed the propagation of wave impact pressure on coastal structures and demonstrated that a sudden fluid-fluid contact can generate transient pressures. Therefore, the entrained air in the flow and the consequent bulk modulus of the two-phase flow are important for the developing transient pressures propagating through it. 


\section{Objective}

The objective of this work was to understand the behaviour of a pressure pulse, generated by a liquid-liquid impact, propagated by a two-phase flow.

\section{Literature review}

Bruce et al. [8] investigated the safety of coastal structures when subjected to the impact generated by the waves. This was done through a historical survey of damaged or destructed structures. The authors concluded that there is no available method that ensures the safety of a coastal structure. According to the authors, the lack of knowledge of the phenomenon of pressure pulses propagation inside the structures is the main concern. However, some progress was achieved.

Wood et al. [9] used a theoretical and an experimental model of waves propagation in water filled cracks. Due to the simplifications adopted in the formation and spreading of the air bubbles in the pressure distribution, the models revealed lack of precision. Small amounts of entrained air in the flow modify significantly the properties of the fluid. Wallis [10] found that the incorporation of air by $1 \%$ reduces the velocity of sound approximately $7 \%$ of its original value. Therefore, additional studies are still necessary.

Wolters and Muller [7] studied the pressures produced from the sudden impact of a wave against a breakwater, in order to check the influence of the impact on the stability of these structures. To measure the impact of the wave, four pressure transducers were installed. The results showed a short duration pressure, ranging from an interval of $0.05 \mathrm{~s}$, despite the existence of pressure peaks. The pressures recorded ranged from 5 to $40 \mathrm{kPa}$.

Muller et al. [3] studied the behaviour of pressure pulses propagating inside a coastal structure and the consequent mechanisms of damages. The first shock wave in the structure was recorded and the results showed that the curves representing the pressure values versus time were similar. The peak pressure ranged from $16 \mathrm{kPa}$ to $22 \mathrm{kPa}$. The analysis indicated a rapid reduction in the magnitude of pressure with time. The authors' assumption to explain the strong energy dissipation was due to the fluid viscosity. They emphasized the scale effect that caused difficulties in understanding the phenomenon. It was concluded that the spread of the pressures from the impact was responsible for enlarging the faults, as large-magnitude forces are developed. Cooker et al. [11] emphasize that the effect of pressure pulses within the joints are pronounced and a detailed study is necessary. The authors reported through their experimental study that, initially, there is a peak pressure of high value and short duration that spreads throughout the joint. These values, however, change along the propagation, which is dependent on the thickness of the joint. It was also observed that small bubbles of air tend to adhere to the wall, causing the water to become a mixture of water and air bubbles that reduces the sound velocity. They found that joints exceeding $0.003 \mathrm{~m}$ wide are more susceptible to destruction due to high internal forces, which are generated. 
Bullock and Obhrai [12] reported impact pressures up to $400 \mathrm{kPa}$ against a wall caused by gravitational waves of less than $3.10 \mathrm{~m}$ high. In most cases, the pressure peaks were studied in time and space to a length of $0.20 \mathrm{~m}$ within the crack of a coastal structure. In the Wolters and Muller [13] study, water containing a percentage of air in the form of micro bubbles caused drastic changes in the compressibility of the air-water two-phase flow. This mechanism of attenuation in the propagation of a pressure pulse is still uncertain, requiring additional research. The authors also note that the small dimensions of the facility tests can interfere in experimental results.

Bullock et al. [4] pointed out that the impact of a wave against a coastal structure might be responsible for its destruction, but the mechanism of this shock is not fully understood. Bullock et al. [14] assert that the experimental facilities constructed by different authors have small dimensions. This may lead to inconsistencies in the results of the experimental model compared to the prototype performance. Taking into account the literature review, it should be pointed out that tests with air incorporation are necessary in order to properly understand the pressure pulse propagation. Nevertheless, mechanisms to adequately measure the incorporated air and the theoretical basing must be developed.

\section{Experimental facility}

Experimental research was conducted in the Hydraulics and Fluid Mechanics Laboratory at UNICAMP. A facility was constructed to simulate the liquid-liquid impact and the pressure pulse propagation, as can be seen in fig. 1. The system consists of an upper reservoir and a lower chamber with a pipe. The upper reservoir, $0.30 \mathrm{~m}$ diameter and $1.00 \mathrm{~m}$ high, is equipped with an opening and

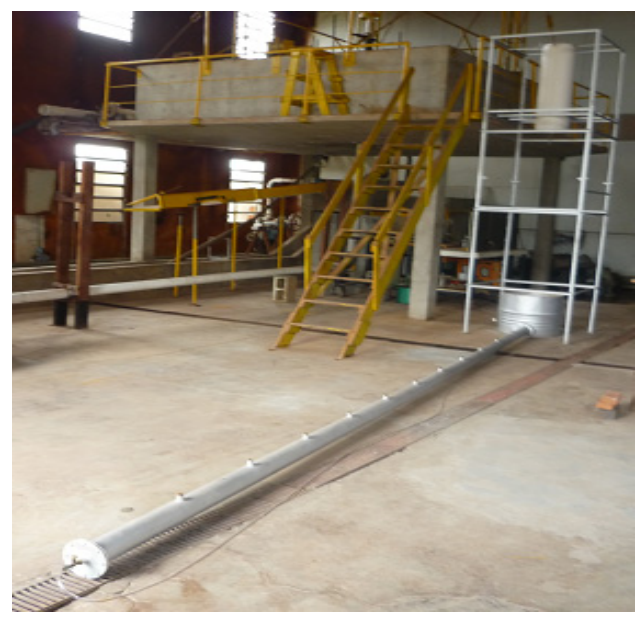

Figure 1: $\quad$ Test facility. 
closing bottom, which is triggered by a lever. This system allows a quasi-instantly opening. A vertical sliding structure supports the upper reservoir, permitting adjustment every $0.15 \mathrm{~m}$. A lower chamber is below this structure. A steel pipe of $6.00 \mathrm{~m}$ long and $0.10 \mathrm{~m}$ diameter is laterally attached to the lower chamber.

Pressure transducers were positioned every $0.50 \mathrm{~m}$ within the pipe. A pressure transducer 0 to $1000 \mathrm{kPa}, 1200 \mathrm{~Hz}$ (Taino [15]) was used. Data acquisition was done using Catman Express and Spider 8 software. At the end of the pipe, a $0.05 \mathrm{~m}^{3}$ compressor injected air and a pressure regulator valve, $0 \mathrm{kPa}$ to $750 \mathrm{kPa}$, was installed.

The structure was fixed at $2.50 \mathrm{~m}$ high from ground level, which enabled the maximum impact energy (Taino [15]). The upper reservoir was then filled with water. After this, the lower chamber and the pipe were filled with water in order to not cause water spilling during the liquid impact. The lever was triggered causing the quasi-instantly liquid-liquid impact and a pressure pulse propagated along the pipe. The pressure transducer registered the instantaneous pressures in the measuring points and recorded the data on the software programs. The first test performed was with no entrained air. After several consecutive tests, the compressor was turned on at different injection pressures of 100, 400 and $700 \mathrm{kPa}$.

\section{Results and analysis}

In order to compare the pressures and minimize the error influence, the graphs were represented by the tendency line of moving average with 50 data. Furthermore, as the registered pressure at every $0.50 \mathrm{~m}$ did not vary significantly (Taino [15]), pressures were acquired at 1.00, 2.00, 3.00, 4.00 and $5.00 \mathrm{~m}$, from the lower chamber.

Figures 2 to 6 present the developed pressures at the different pressures of air injection, which are 100,400 and $700 \mathrm{kPa}$. It can be seen that after each peak

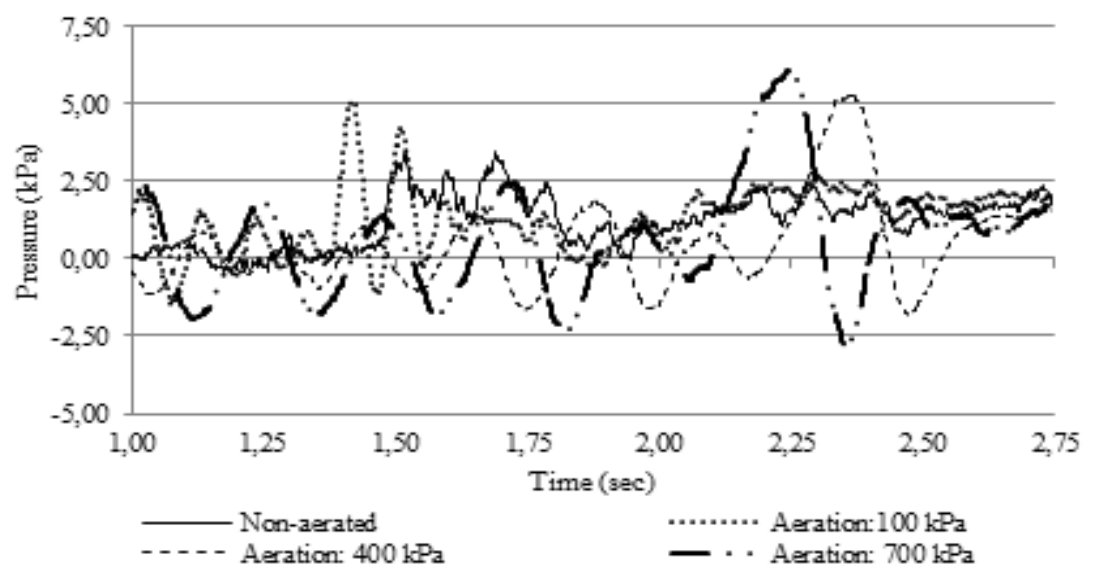

Figure 2: $\quad$ Pressure versus time at $1.00 \mathrm{~m}$ distance. 
there is a tendency to a faster stabilization with air injection than without it. For the non-aerated situation, the pressure pulse takes longer time to stabilize farther to the lower chamber. This behaviour may be due to the constant flow of air that was heading in the opposite direction of the impact flow. Also, it has to be noted that the peaks do not coincide. This is because of the use of only one transducer at a time.

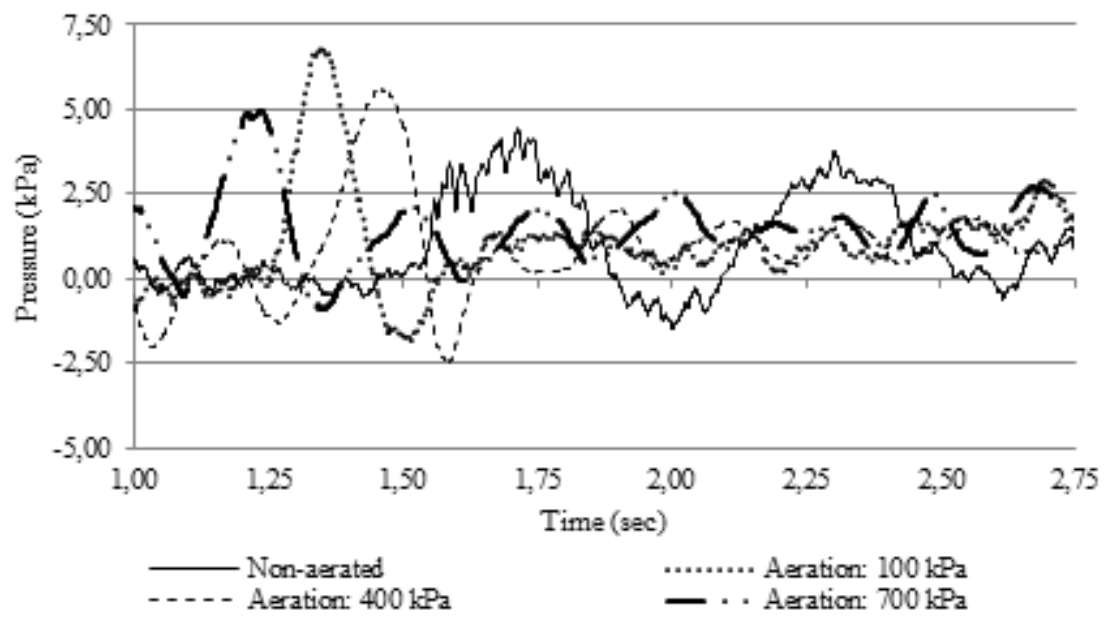

Figure 3: $\quad$ Pressure versus time at $2.00 \mathrm{~m}$ distance.

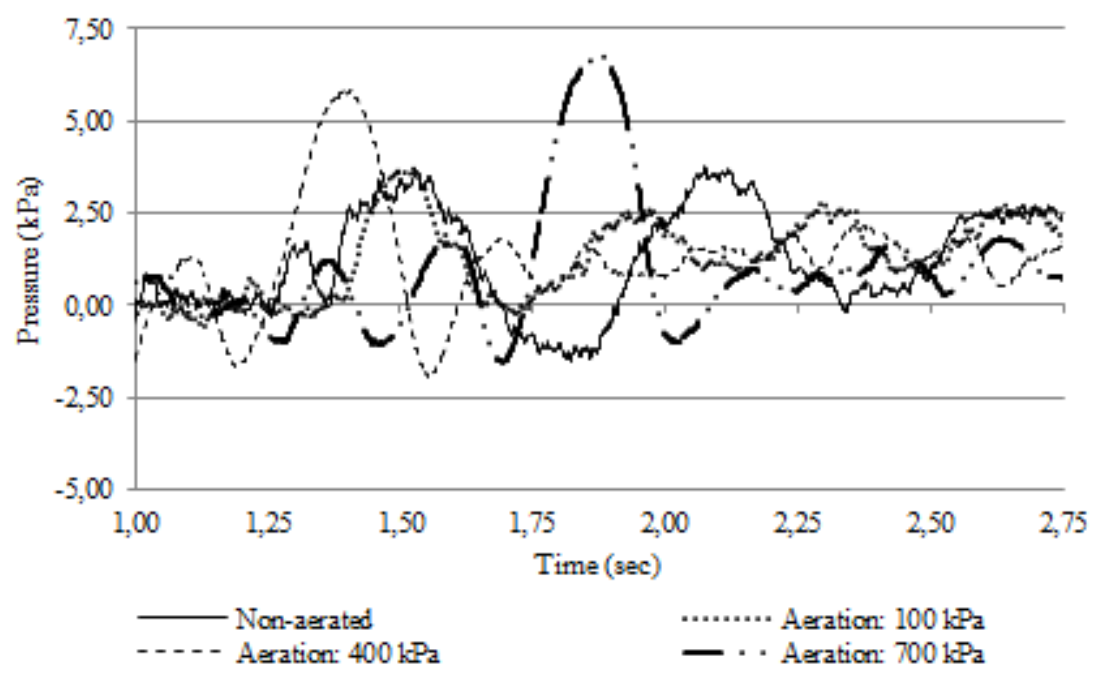

Figure 4: $\quad$ Pressure versus time at $3.00 \mathrm{~m}$ distance. 


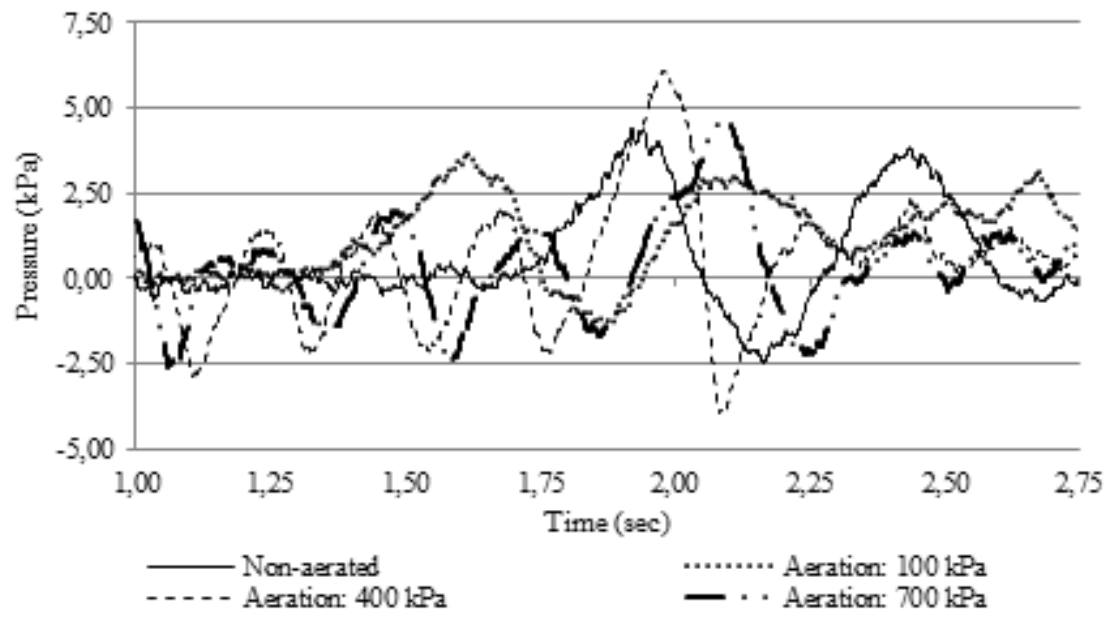

Figure 5: $\quad$ Pressure versus time at $4.00 \mathrm{~m}$ distance.

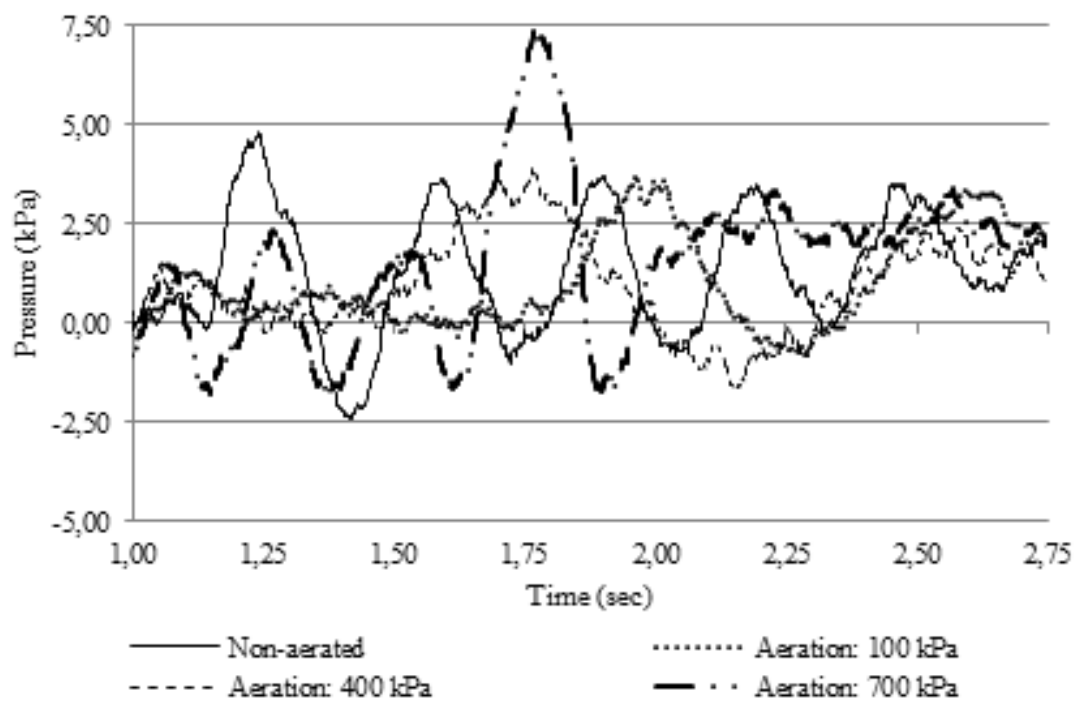

Figure 6: Pressure versus time at $5.00 \mathrm{~m}$ distance.

In order to verify the way the pressure pulses were affected by the entrained air, graphs from fig. 7 to fig. 10 are presented. It can be observed that the greater the pressure of air injection, the higher the pressure disturbance.

It should be pointed out that figs. 2 to 10 were plotted with the moving average in order to present the pressures development and to verify the behavior of the wave in time and space. However, the verification of maximum and minimum pressures achieved gets impaired. Thus fig. 11 and fig. 12 were 
elaborated in order to accurately compare the peak values of pressure. The peak pressures were attenuated close to the lower chamber due to the presence of air in the water. Howsoever, at distance of $5.00 \mathrm{~m}$, near the compressor location, the peak pressure tends to increase probably due to its presence.

Likewise, the minimum pressures were plotted in Figure 12. It can be seen that the pressures have been attenuated with aeration for most of the cases.

In both fig. 11 and fig. 12 show a pressure increase near to the compressor. Also, the tendency of decrease of the pressure peaks could not be stated, as greater peaks were observed for the aeration at $700 \mathrm{kPa}$ than those at $400 \mathrm{kPa}$.

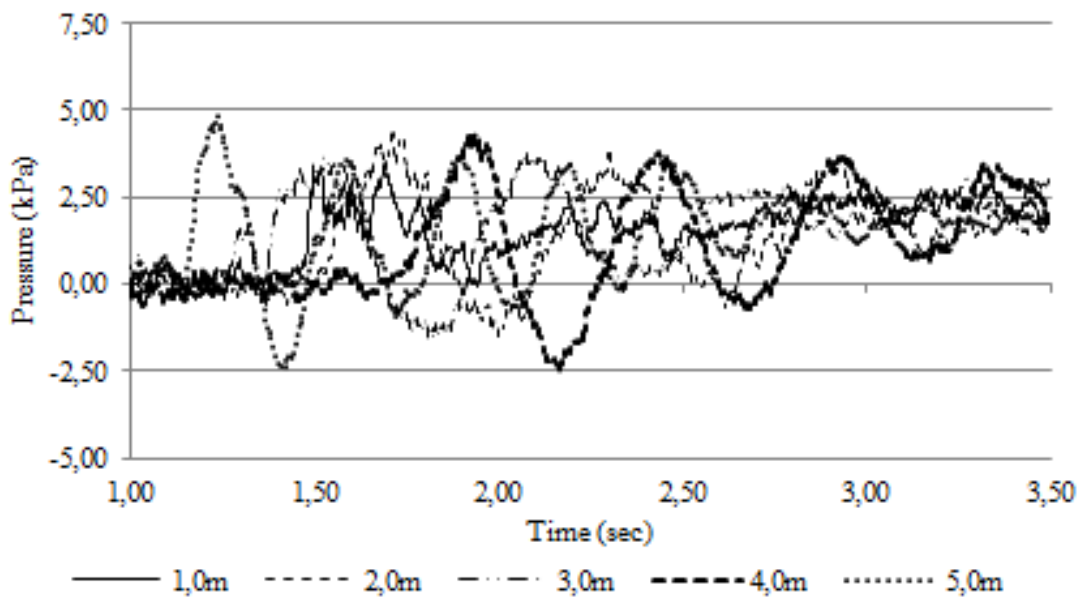

Figure 7: $\quad$ Pressure versus time for non-entrained air.

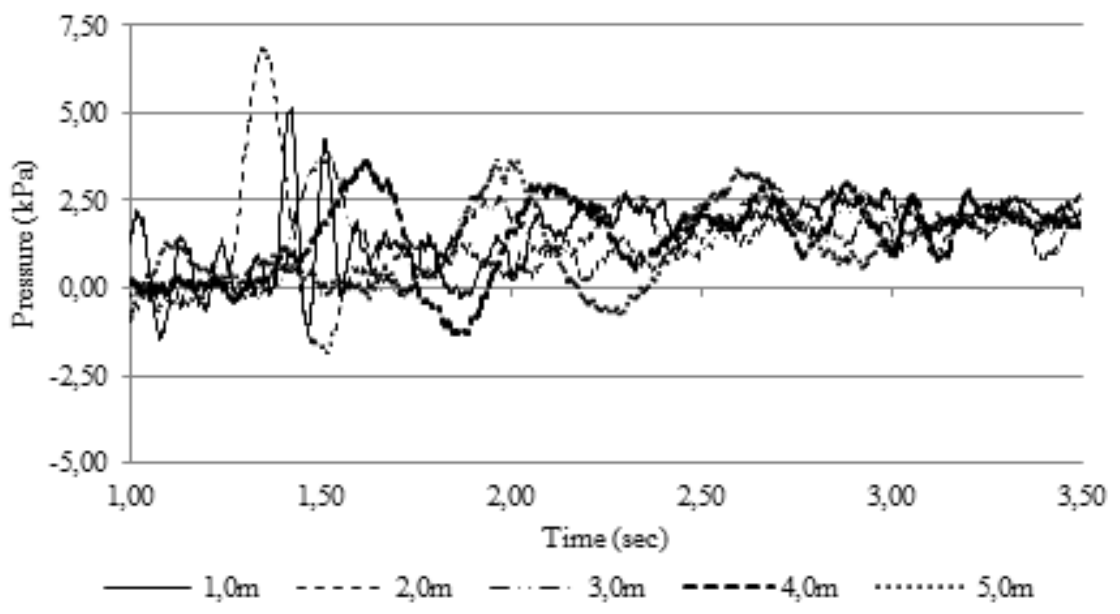

Figure 8: $\quad$ Pressure versus time for entrained air at $100 \mathrm{kPa}$. 


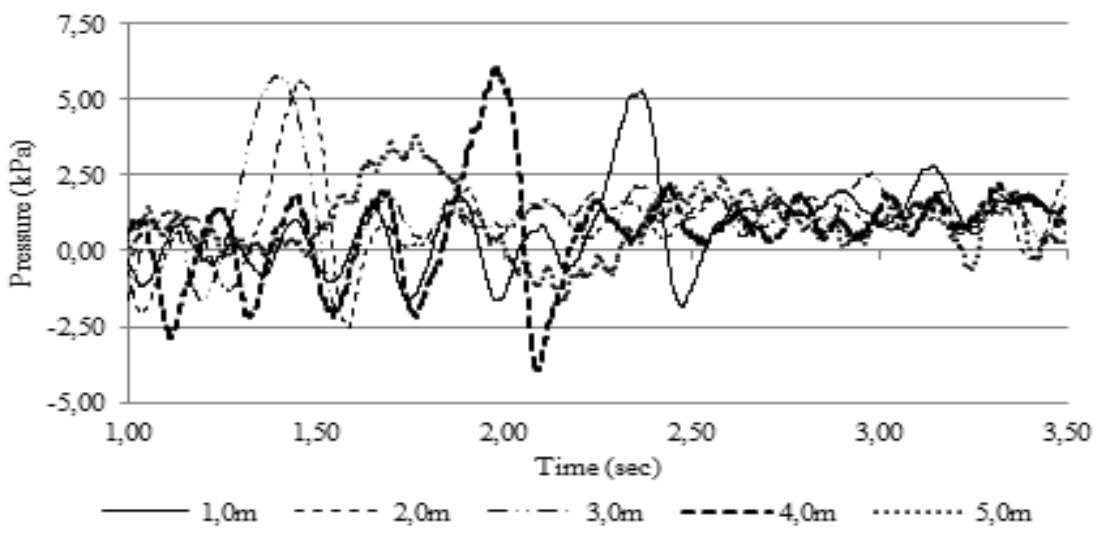

Figure 9: $\quad$ Pressure versus time for entrained air at $400 \mathrm{kPa}$.

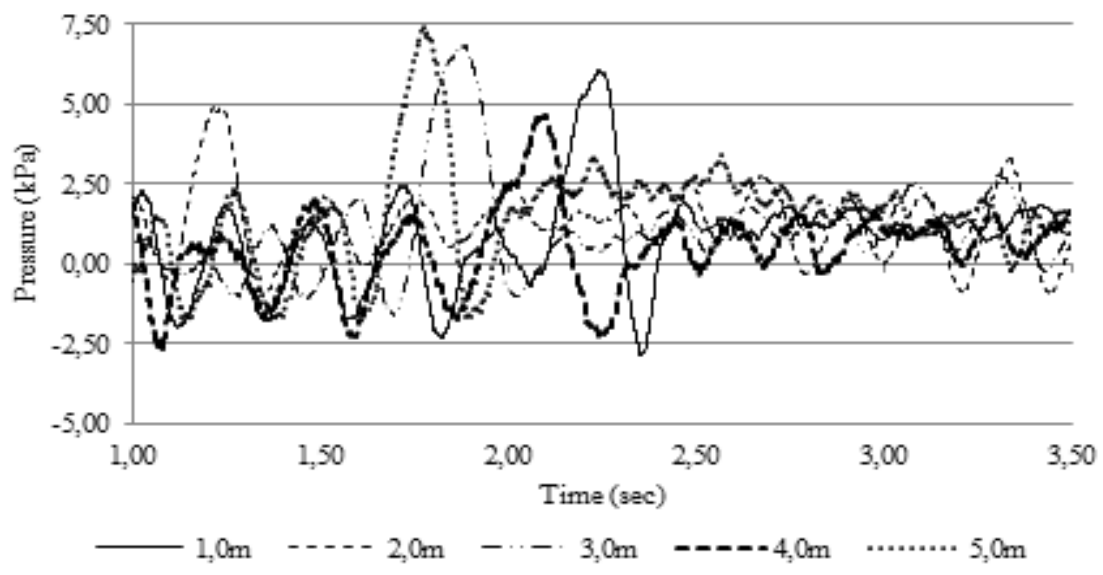

Figure 10: $\quad$ Pressure versus time for entrained air at $700 \mathrm{kPa}$.

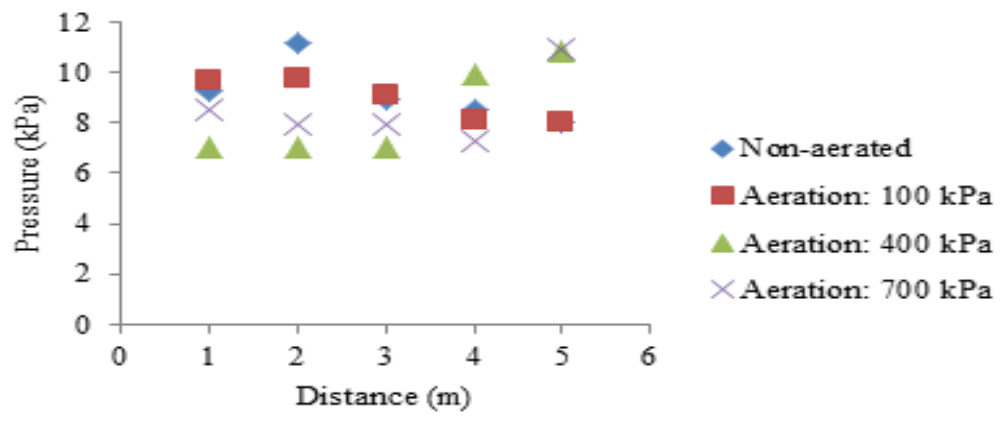

Figure 11: Maximum pressure in the measured points. 


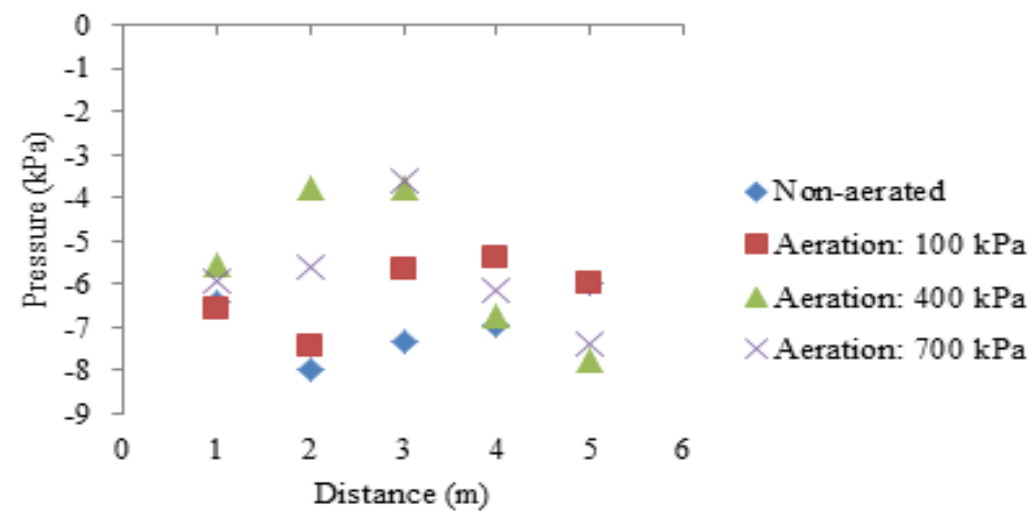

Figure 12: $\quad$ Minimum pressure in the measured points.

\section{Conclusion}

It can be concluded that the impact of liquid-liquid generates pressure transients of high intensity and the duration depends on the distance of the impact source and the presence of air in the mixture. It cannot be confirmed a tendency of attenuation of pressure surges, according to the entrained air. Additional tests should be performed in order to find a tendency of the peaks attenuation.

The presence of air in the flow decreased peak pressures generated by the impact liquid-liquid, as also verified Bullock et al. [4]. The highest pressures occurred at the initial part of the pipe in the case without aeration, which is in accordance with the analysis of Wolters and Muller [7].

In the case of an existing crack, the higher the frequency of the shock of the mass of water, the greater the tendency to extend the crack. This is because there is always a high magnitude of transient pressure developed. As a suggestion, the way the joints or cracks are extended, regarding the pressure peaks and their frequency, should be studied in the future.

\section{Acknowledgements}

To PIBIC (Programa Institucional de Bolsas de Iniciação Científica da UNICAMP) for undergraduate scholarship, to José Luíz Trinchinato, Technician of the Laboratory of Hydraulics and Fluid Mechanics and to Benjamin Williams, student at University of Missouri, for text reviewing.

\section{References}

[1] Bollaert, E. \& Schleiss, A. (2003), Scour of rock due to the impact of plunging high velocity jets. Part I: A state-of-the-art review. Journal of Hydraulic Research, 41(5), pp. 451-464. 2003. 
[2] Betancourt, M.G., Levantamiento de una losa de piso sometida a un flujo macroturbulent. Doctoral thesis-Universidad Nacional de Colombia: Medellín, 2010.

[3] Muller, G., Hull, P., Allsop, W., Bruce T., Cooker, M. \& Franco, L. Wave effects on blockwork structures: model tests. Journal of Hydraulic Research, 40 (2), pp.117-124, 2002.

[4] Bullock, G.N., Crawford, A.R, Hewson, P.J., Walkden, M.J.A. \& Bird, P.A.D., The influence of air and scale on wave impact pressures. Coastal Engineering, 42, pp.291-312. 2001.

[5] Bagnold, R.A., Committee on wave pressures: interim report on wavepressure research. Journal of the Institute of Civil Engineers, 12, pp. 201226, 1939.

[6] Cox, S. J. \& Cooker, M. J., The pressure impulse in a fluid saturated crack in a sea wall. Coastal Engineering, 42, pp. 241-256. 2001.

[7] Wolters, G., Muller, G., Pressure transients and energy dissipation in liquid-liquid impacts. Journal of Hydraulic Research, 42 (4) pp.440-445, 2002.

[8] Bruce, T., Allsop, W., Cooker, M., Franco, L. \& Muller, G. How safe are blockwork breakwaters and seawalls against wave attack? Proc. of the 27th ICCE, Ed: R.J. Cox, Sidney, paper 179, 2000.

[9] Wood, D.J., Peregrine, D.H. \& Bruce, T., Wave impact on a wall using pressure-impulse theory I: Trapped air. Journal of waterway, port, coastal and ocean engineering.126(4), pp.182-190, 2000.

[10] Wallis, G.B., One dimensional two-phase flow, McGraw- Hill: New York, 408p, 1969.

[11] Cooker, M.J., Wolters, G. \& Muller, G., Characteristics of pressure pulses propagating through water-filled cracks. Coastal Engineering, 49, pp.83-98, 2003.

[12] Bullock, G. \& Obhrai, C. Wave impact loads at large and full scale. Coastal Zone Network. Online. http://cozone.org.uk/ovcrtop/15-GB.pdf

[13] Wolters, G. \& Muller, G., Impact forces on the sea bed created by wave uprush. Proc. of the ICOPMAS, Bender Abbas/Iran, paper 605, 2004.

[14] Bullock, G.N., Obhrai, C., Peregrine, D.H \& Bredmose, H, Violent breaking wave impacts. Part 1: Results from large-scale regular wave tests on vertical and sloping walls. Coastal Engineering, (54) pp. 602-617, 2007.

[15] Taino, R., Pressões transitórias geradas no impacto de uma onda contra o paramento de uma estrutura hidráulica, Iniciação Científica-Universidade Estadual de Campinas: Brasil, 2010. 